\title{
Protein sulphydryl depression during adjuvant arthritis
}

\author{
A. LORBER, J. LEEB, P. CARROLL, JR., W. BAUMGARTNER, AND V. HILL \\ From the Clinical Immunology and Rheumatic Disease Section, Department of Medicine, University of \\ Southern California, Los Angeles, and the Veterans Administration Hospital, Long Beach, California
}

\begin{abstract}
Lorber, A., Leeb, J., Carroll, P., Jr., Baumgartner, W., and Hill, V. (1975). Annals of the Rheumatic Diseases, 34, 346-349. Protein sulphydryl depression during adjuvant arthritis. The changes in plasma protein sulphydryl level were measured during the course of adjuvant-induced arthritis in rats. Major depressions in the plasma sulphydryl level occurred at the onset of adjuvant disease, and the extent of the depression was related to the severity of the disease. Plasma sulphydryl levels remain unchanged when the systemic arthritis is suppressed by inclusion of a competing antigen in the adjuvant. Changes in sulphydryl content of the plasma were shown not to be due to weight loss or decrease in plasma protein level.
\end{abstract}

Deficiency of sulphydryl (SH) levels of plasma proteins has been reported in patients with connective tissue disorders (rheumatoid arthritis, systemic lupus erythematosus, rheumatoid vasculitis) (Lorber, Bovy, and Chang, 1971). A study was conducted using adjuvant arthritis (AA) as a model to gain insight into the significance of this $\mathrm{SH}$ depression with respect to the aetiology and/or pathogenesis of such disorders. The systemic nature of $\mathrm{AA}$ is indicated by the widespread biochemical disturbances which accompany the chronic joint inflammation. In this sense, AA may be comparable to the above human collagen vascular disorders. The actual development of AA can be readily quantified and distinguished from an initial phase of acute inflammation at the site of injection of the adjuvant, thus providing an excellent experimental vehicle for studying the SH depression during the various phases of the disease.

Specifically, this study attempts to establish the effect on plasma $\mathrm{SH}$ values of the initial, acute inflammatory phase characterized by inflammation of the injected joint and of the various phases of AA. Changes in serum SH levels at these various phases of the disease were compared to the arthritis score, changes in plasma protein levels, and body weight. SH values were also determined in animals in which the AA was suppressed by a competing antigen without, however, influencing the initial inflammatory response.

\section{Materials and methods}

For all experimental and control groups, 5 male Lew strain rats (Microbiological Associates) weighing 150-259 $\mathrm{g}$ initially, were used. Adjuvant arthritis was induced by intradermal injection of $0.10 \mathrm{ml}$ Freund's complete adjuvant into a foot pad of the left hind paw. The adjuvant was prepared by suspending Mycobacterium butyricum (Difco Laboratories) in paraffin oil $(6.0 \mathrm{mg} / \mathrm{ml})$.

The arthritis score was used as an index of the severity of the AA and was determined by observation of the extent of swelling, lesions, and redness of each joint, including the tail, with scores of 0 to 4 being assigned to each joint. The maximum score for one animal was 20.

Blood samples were collected into heparinized tubes by amputation of the tip of the tail. Plasma protein $\mathrm{SH}$ was determined radiochemically by addition of $0.1 \mathrm{ml}$ plasma to $0.2 \mathrm{ml}{ }^{203} \mathrm{Hg} p$-chloromercuribenzene sulphonic acid (PCMBS, $1.18 \mathrm{mmol} / \mathrm{l}$ in $0.09 \% \mathrm{NaCl}$ ), to a final volume of $1.5 \mathrm{ml}$ with water followed by precipitation with $1.5 \mathrm{ml}$ of $7 \%$ trichloroacetic acid (TCA) and centrifugation. Precipitates were washed twice with $3.75 \%$ TCA, and protein bound ${ }^{203} \mathrm{Hg}$ in the precipitates was counted in a well scintillation spectrometer. When larger sample $\mathcal{N}$ volumes were available, serum sulphydryl levels were also measured by argentometric titration, and no significant differences were found. In those occasional samples which $\omega$ showed signs of haemolysis, corrections were made for $\bar{\sigma}$ heme protein $\mathrm{SH}$ in the plasma samples by determining 0

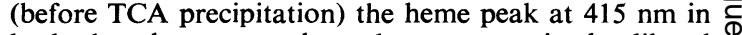
both the plasma sample and an appropriately diluted $\stackrel{\infty}{\oplus}$ haemolysate of cells from the same animal. The haemolysate was analysed for $\mathrm{SH}$ in the same manner as the 
plasma. From the calculated SH per heme OD in the haemolysate and the OD of the heme in the plasma sample, the heme protein $\mathrm{SH}$ in the plasma sample was calculated and subtracted from the total protein SH.

Suppression of AA with competing antigen (Pearson and Wood, 1964; Gery and Waksman, 1967) was achieved by homogenizing human IgG (7S fraction) with Freund's complete adjuvant before injection. Booster shots of the IgG alone (in saline) were administered on days 8,26 , and 44. The production of antibody against human IgG was monitored by means of a latex agglutination test (Hyland RA test). Albumin was measured fluorometrically (Rees, Fildes, and Laurence, 1954). Total plasma protein was determined by the biuret method (Reinhold, Seligson, Schreiner, Riddle, Sharon, and Vanderan, 1953).

\section{Results}

The serial changes which occur in plasma SH levels during the course of adjuvant arthritis disease are shown in Fig. 1. It can be seen that the disease can be divided into 5 different phases on the basis of disease activity (Baumgartner, Beck, Lorber, Pearson, and Whitehouse, 1974). During the nonimmune inflammatory period (phase I), a rapid swelling of the injected foot takes place, accompanied by a slight decline in plasma SH levels. No significant swelling is seen in the uninjected feet during this period. The onset of AA is signified by the appearance of marked swelling in all extremities, occurring between 8 and 18 days after injection (phase II). Plasma SH levels show a marked decline during this period, and numerous other signs of disseminated disease (vas-

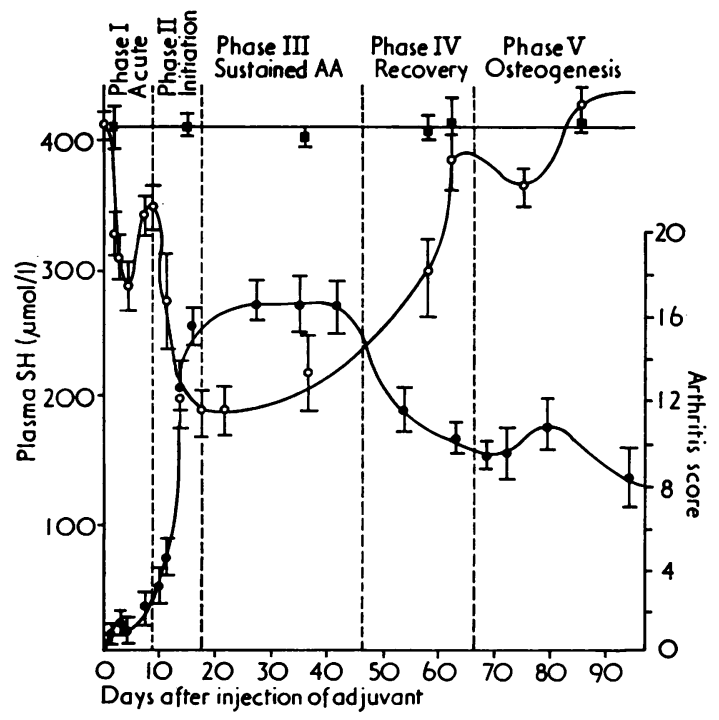

FIG. 1 Plasma SH levels and arthritis score during adjuvant arthritis, demonstrating significant sustained suppression in SH levels during phase III of adjuvant arthritis. $\square$, plasma SH of normal rats; O, plasma $\mathbf{S H}$ of adjuvant arthritic rats; •, arthritis score of adjuvant arthritic rats

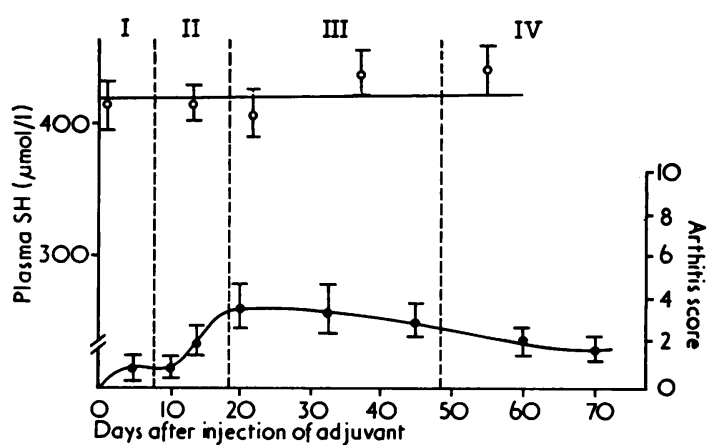

FIG. 2 Plasma SH levels and arthritis score during suppression of adjuvant arthritis. Essentially no decline is observed in plasma $\mathrm{SH}$ levels despite acute inflammation of the injected joint, and normal response to the human $\mathrm{IgG}$. O, plasma $\mathrm{SH} ; \bullet$, arthritis score

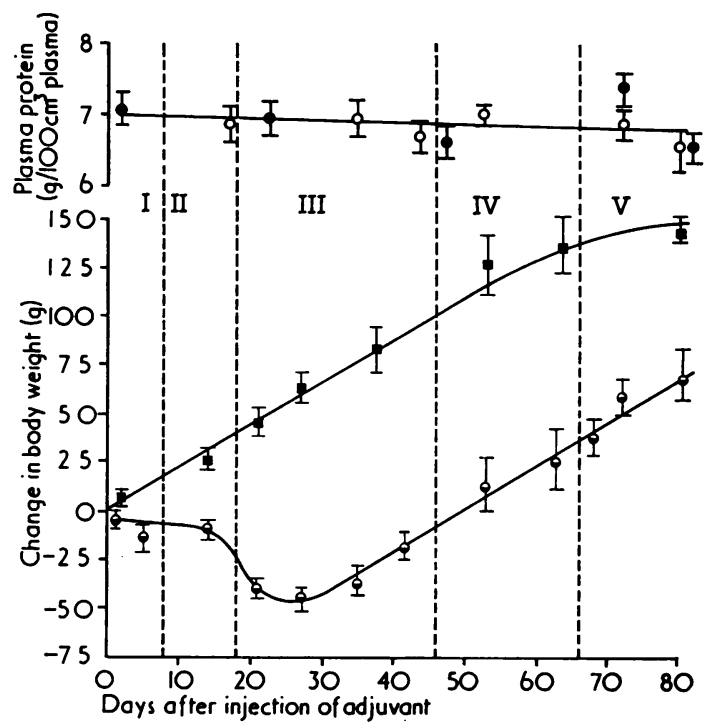

FIG. 3 Plasma protein levels and changes in body weight during adjuvant arthritis. Plasma protein of adjuvant arthritic rats remains at normal levels, although marked declines are noted in their body weight. $\bullet$, normal plasma protein; $O$, adjuvant plasma protein; $\square$, normal weight; $\ominus$, adjuvant weight

cular lesions, balanitis, splenomegaly) become evident. Plasma SH levels continue to be markedly depressed ( $P>0.05$ by the ' $t$ ' test) during the sustained phase of the disease (phase III), which includes the period from about day 18 to day 48 . During the recovery phase of the disease (phase IV, 50-65 days after injection), many of the clinical manifestations of the disease disappear as $\mathrm{SH}$ levels return to normal.

The temporary decrease in SH values which accompanied a slight rise in the arthritis score between 70 and 80 days may have been due to a relapse, 
which is known to occur in AA. The arthritis score does not return to zero due to permanent joint deformity and osteogenesis.

When the sustained phase of AA (phase III) was blocked by the addition of human IgG to Freund's adjuvant, the decline in plasma SH did not take place nor did the development of systemic lesions or generalized arthritis (Fig. 2). Acute inflammation was limited entirely to the injected joint (phase I). Evidence of humoral immune response to the IgG was shown by the development of antihuman IgG titre, ranging from 160-1280 reciprocal dilutions. This response, however, was not correlated with depletion of plasma protein SH.

Although adjuvant rats lose substantial amounts of body weight during the course of the disease, total plasma protein content remains relatively stable (Fig. 3). Some changes in the albumin/globulin ratio are seen, but similar alterations can be observed in normal rats when restricted to $50 \%$ of the normal food intake (which is equal to the most depressed food intake observed during AA). These starved animals suffered weight losses similar to the AA rats and similar alteration in $\mathrm{A} / \mathrm{G}$ ratio (Zahiri, Gagnon, Ayotte, and Laurin, 1969), but there is no decline in SH content with food deprivation (Table).

\section{Discussion}

It appears that the sulphydryl depression of plasma proteins in adjuvant arthritis is associated with the protracted inflammatory phase of the disease. The major depression of $\mathrm{SH}$ level occurs during this phase, and those changes which occur during the acute phase are more moderate, and appear to be transitory. Other biochemical changes have been reported to occur in AA, including depressed serum albumin levels, raised fibrinogen and $\alpha$-2-macroglobulins, and impaired liver microsomal oxidase activity (Lowe, 1964; Weimer, Wood, and Pearson, 1968; Beck and Whitehouse, 1973). All of these changes, however, are expressed during the initial acute inflammatory phase and can be induced by agents such as croton oil and carrageenan without leading to AA (Goldstein, Shemano, Demeo, and Beiler, 1967; Varsa-Handler, Handler, and Gordon, 1967; Glenn, Gray, and Kooyers, 1965).

The observed SH depression was not due to the acute inflammation, since those rats in which AA was suppressed by the competing antigen did not show any depression. Neither was the depression due to decreased food consumption or loss of body weight, since starvation of normal animals did not lead to SH declines. Although the albumin/globulin ratio did vary during AA, the declines noted in albumin level could not account for more than one half of the decrease in $\mathrm{SH}$, assuming $1 \mathrm{~mol} \mathrm{SH} / \mathrm{mol}$ albumin. Similarly, reports have shown wide fluctuations in plasma SH of rheumatoid arthritic patients, unre- क lated to major changes in the composition of plasma $\vec{\circ}$ proteins (Lorber, and others, 1971). This suggests that oxidation of protein SH groups, or formation of new proteins deficient in $\mathrm{SH}$, is occurring. Increased heterogeneity in electrophoretic $\widehat{\partial}$ patterns has previously been reported (Lorber, and $\underset{\oplus}{\omega}$ others, 1971). Biochemical abnormalities, such $t$ as albumin changes and $\mathrm{SH}$ depression, may both $\omega$ result from a more basic liver malfunction, the 0 existence of which is indicated by the impaired drug $\stackrel{\circ}{\supset}$ hydroxylation in the liver in AA (Beck and Whitehouse, 1973).

Changes in SH levels similar to those observed in the AA model could be postulated as contributory or aetiological factors for human rheumatoid disease $\vec{\theta}$ on the following basis:

(1) Sulphydryl depression can lead to abnorm protein configuration (e.g. aggregation of IgC̣ which in turn serves as an antigenic stimulus for autoimmune process.

(2) Depletion of $\mathrm{SH}$ groups in the local environment of immunocompetent cells (e.g. in the $\overline{\vec{\sigma}}$ spleen, thymus, or lymph nodes) could alter or $\exists$ disturb the normal function of lymphocytes residing there. Sulphydryl groups, and their availability to the many enzyme and membrane systems, may be essential for maintenance of the normal immune state.

(3) The activation of complement $\mathrm{C} 3$ and neutral collagenase, and loss of normal lysosomal permeability barriers, may also be associated with decrease in protein SH levels.

Although on theoretical grounds the sulphydryl $\frac{7}{2}$ depletion appears to be a plausible factor in the induction and/or pathogenesis of adjuvant arthritis, $\widetilde{N}$

Table Changes in plasma proteins upon starvation in normal animals

\begin{tabular}{|c|c|c|c|}
\hline $\begin{array}{l}\text { Days of } \\
\text { starvation* }\end{array}$ & $\begin{array}{l}\text { Loss in body } \\
\text { weight }(g) \dagger\end{array}$ & $\begin{array}{l}\text { Plasma SH } \\
\text { ( } \text { umol/g protein) }\end{array}$ & $\begin{array}{l}\text { Albumin/globulin } \\
\text { ratio }\end{array}$ \\
\hline $\begin{array}{r}0 \\
10 \\
20\end{array}$ & $\begin{array}{l}0 \\
63 \pm 9 \\
104 \pm 21\end{array}$ & $\begin{array}{l}5 \cdot 9 \pm 0 \cdot 2 \\
5 \cdot 6 \pm 0 \cdot 2 \\
6 \cdot 1 \pm 0 \cdot 4\end{array}$ & $\begin{array}{l}0.54 \pm 0.05 \\
0.31 \pm 0.02 \\
0.65 \pm 0.03\end{array}$ \\
\hline
\end{tabular}


the cause of the depression has not been established. One possible mechanism, which will be discussed in a subsequent publication, is that the SH depression is caused by an increase in oxidative stress which, in turn, leads to damage of the membranes of various cell organelles (lysosomes, mitochondria, etc.). The increase in oxidative stress may be due to the produc- tion of hydrogen peroxide as a result of enhanced phagocytic activity of polymorphonuclear leucocytes and macrophages.

This study was supported in part by grant no. PH-86-68200 , and by the American and Southern California Chapter of The Arthritis Foundation.

\section{References}

Baumgartner, W. A., Beck, F. W. J., Lorber, A., Pearson, C. M., and Whitehouse, M. W. (1974) Proc. Soc. exp. Biol. (N.Y.), 145, 625 (Adjuvant disease in rats: biochemical criteria for distinguishing several phases of inflammation and arthritis)

BeCK, F. J., AND WhITEHOUSE, M. W. (1973) Biochem. Pharmacol., 22, 2453 (Effect of adjuvant disease in rats on cyclophosphamide and isophosphamide metabolism)

Gery, I., AND WAKSMAN, B. H. (1967) Arthr. and Rheum., 10, 240 (Competition of antigens in adjuvant disease of rats)

Glenn, E. M., Gray, J., AND Kooyers, W. (1965) Amer. J. vet. Res., 26, 1195 (Chemical changes in adjuvant-induced polyarthritis of rats)

Goldstein, S., Shemano, I., Demeo, R., ANd Beiler, J. M. (1967) Arch. int. Pharmacodyn., 167, 39 (Antiinflammatory activity of several irritants in three models of experimental inflammation in rats)

LoRber, A., Bovy, R. A., AND ChANG, C. C. (1971) Metabolism, 20, 446 (Sulfhydryl deficiency in connective tissue disorders: correlation with disease activity and protein alterations)

Lowe, J. S. (1964) Biochem. Pharmacol., 13, 633 (Serum protein changes in rats with arthritis induced by mycobacterial adjuvant)

Pearson, C. M., AND Wood, F. D. (1964) Arthr. and Rheum., 7, 337 (Inhibition of adjuvant arthritis by some protein antigens)

Rees, V. H., Fildes, J. E., AND LauRence, D. J. R. (1954) J. clin. Path., 7, 336 (The dye-binding capacity of human plasma determined fluorometrically and its relation to the determination of plasma albumin)

Reinhold, J. G., Seligson, D., Schreiner, G. E., Riddle, L. V., Sharon, W., and Vanderan, M. (1953) 'Total protein, albumin, and globulin', in 'Standard Methods of Clinical Chemistry', ed. M. Reiner, vol. 1, p. 88. Academic Press, New York

Varsa-Handler, E. E., Handler, E. S., ANd Gordon, A. S. (1967) Proc. Soc. exp. Biol. (N. Y.), 124, 562 (Quantification of cellular influx into the croton oil-induced pouch. Effects of prednisolone)

Weimer, H. E., Wood, F. D., AND Pearson, C. M. (1968) Canad. J. Biochem., 46, 743 (Serum protein alterations in adjuvant-induced arthritis)

Zahiri, H., Gagnon, J., Ayotte, R., ANd Laurin, C. A. (1969) Canad. med. Assoc. J., 101, 269 (Adjuvant experimental polyarthritis) 